\title{
Analysis of Factors Determining Financial Literacy using Structural Equation Modelling\#
}

\author{
R. Venkataraman ${ }^{1 *}$ and Thilak Venkatesan ${ }^{2}$ \\ 'Dean, Presidency College, Bangalore, India \\ ${ }^{2}$ Research Scholar, Bharathiar University, Coimbatore, India
}

\begin{abstract}
Financial literacy will enable better decision making and efficient management of funds. The knowledge of basic foundations of time value can result in building a robust portfolio. The recent initiatives by the government on financial inclusion aids in promoting faster access to transfer benefits. The policy implementation on bank accounts for all, linking of Aadhar to the accounts, insurance of minimum sum assured for all and the basic annuation schemes are some of the initiatives well devised by the Modi Government. The RBI on the other hand, had initiated various financial literacy programmes to have significant inclusion. The key to successful inclusion is financial literacy. In this context, the paper attempted to identify factors that determine financial literacy. The data was collected through primary sources trough structured questionnaire. The tools used for the analysis was confirmatory factor analysis and structural equation modelling. The factors identified were financial attitude, behavioural factors, financial knowledge and influence and among the factors financial knowledge and influence were observed to predict financial literacy.
\end{abstract}

Keywords: Behavioural Finance, Financial Literacy, Financial Inclusion

JEL Classification: G02, D91

\section{Introduction}

Financial literacy refers to the knowledge and capability to make informed and effective decisions of financial resources. Financial literacy is the convergence of financial, credit and debt management and the understanding that is necessary to make money-wise or financially responsible decisions i.e., decisions that are vital to our everyday lives Fatemeh Kimiyaghalam \& Stanley Yap, (2017). Lack of financial literacy leads to ineffective role in the financial inclusion mechanism. The transmission of benefits to the public is by large a problem in a country like India. The benefit of one such plan by the Modi government is the direct transfer of subsidy in case of LPG is much appreciated. A higher percentage of financial literacy would facilitate efficient management of risk and thereby aids in avoiding pitfalls. Nations globally have populations facing trouble in understanding the basics of finance.

The level of financial literacy largely depends upon the level of education and income. Prior studies prove that a highly educated person with high income can also be unaware about financial issues as a person who isn't well educated and having a lower income. A survey conducted by the Organization for Economic Co-operation and Development (OCED) found that opting an investment that is crucial as retirement savings plan was much more traumatic than a dentist visit. Individuals will not be able to choose the right investment or savings plan for themselves and may be at risk or fraud if they are not financially literate (OECD, the impor-

\footnotetext{
*Email: venkatramana.r@presidency.edu.in

\#This is the revised and modified version of the article, presented in the $6^{\text {th }}$ International Conference on Emerging Trends in Finance, Accounting and Banking, SDMIMD, August 2017.
} 
tance of Financial education 2006). The Organization for Economic Co-operation and Development (OCED) conceptualizes financial literacy as a mixture of awareness, knowledge, skills, attitude and behaviour required to make financial decisions and eventually achieve individual financial well-being (OECD INFE 2011). A substantial issue with financial literacy is the identification factors influencing and their relationship.

Prior studies highlight the methods used in measuring financial literacy and its inherent use in decision making, the factors that were considered were devised separately and the present study was focused to consider all factors in tandem to observe which among the factor is a key determinant of financial literacy. The structure of the paper abridges the prior studies, the research gap, and lists various factors that affect the financial literacy. The methodology used is briefed followed by the research findings.

\section{Review of Literature}

Annamaria Lusardi et. al, (2009) examined how well equipped, young make financial decisions. They observed that a majority of young adults were not been able to make decisions in finance. The analysis was done using multivariate analysis; they observed educational attainment and cognitive ability as major predictors of financial decision making. They observed that the basic knowledge of interest rates, inflation, and risk diversification were only $33 \%$ among young adults. The relationship between financial literacy, socio-demographic characteristics and family financial sophistication were significant. They observed educated female student posses less knowledge on diversification that the male counterparts whose parents are into savings and invested in stock market.

Mohamad Fazli Sabri et. al, (2010) examined sociocultural factors on the financial literacy among the Malaysian college students. The methods for analysis were t-tests, ANOVA and regression. They concluded that family finance discussions had a significant relationship on financial literacy. They also observed that the Chinese ethnicity students scored lower on financial literacy.

http://www.informaticsjournals.com/index.php/sdmimd | Vol 9 | Issue 1 | March 2018
Kharchenko et. al, (2011) examined the implications of financial literacy and its determinants for saving behaviour in Ukraine. Their methodology was grounded on previous empirical and theoretical findings. They suggested that literacy does not have a direct impact on savings when controlling for wealth. Although, since literacy and wealth are correlated, they argued that financial literacy may have an indirect impact on savings by influencing wealth.

William T. Sucuahi, (2013) observed the demographic factors influencing financial literacy among micro entrepreneurs. The methods adopted were survey questionnaire method and regression technique. Gender was insignificant in predicting the micro entrepreneur's financial literacy.

Puneet Bhushan et. al, (2013) analysed the influence of demographic and socioeconomic factors on financial literacy among the salaried individuals. The methodology was a survey approach and they observed a moderate level of financial literacy.

Aren S, (2014) evaluated prior studies on financial literacy, and highlighted the key issues such as its definitional issues and the determinants. The researcher proposed that financial literacy as an endogenous and various methods in measuring the same. He asserted to determine the effect of financial literacy on determining investment preferences.

Trizah Thara Mbarire et. al, (2014) determined the effect of demographic characteristics, and socioeconomic factors among employees upon financial literacy. They aimed to establish the effect of various information sources and financial advisory on financial literacy among the employees. The methods adopted were descriptive research design and a survey method. The results concluded by them proved that the employees' level of knowledge is generally low.

Victoria Vyvyan et. al, (2014) examined the underlying determinants of financial capability by that influence financial literacy. A qualitative research approach was used and they observed confidence, self-esteem, and self-belief as the key determinants of financial literacy. 
The results firmly opined a short-term focus as a key financial effectiveness inhibitor.

Lereko Rasoaisi et. al, (2015) examined the financial knowledge of students at National University of Lesotho, they used descriptive statistics method of analysis in the form of frequency tables and charts and the results indicated that the male students were financially knowledgeable than their female counterparts.

Islamoglu M et. al, (2015) investigated various factors that affect investment behaviour among bankers. The factors considered were income level, behavioral characcteristics, tracking behaviour, banking and payment decisions and investor attitude. The study observed high correlation among concious investor behaviour and banking and payment behaviour.

Sanjib Das, (2016) observed the demographic factors that determine the literacy. The approach to measure financial literacy was classified into objective approach through questionnaires and self assessment mode. The researcher stressed the need for a structured education program to facilitate and improve literacy as it a vital skill across the population.

\subsection{Research Gap}

The review of literature suggested that the various studies focussed on demographic factors, socio-economic factors and behavioural factors separately. The factors influencing financial literacy can be considered together to find which among the factors is having a significant influence. In this context, the study focussed to find the factors prompting financial literacy and considered all the factors to find the influencing factor to enable easier transmission of financial knowledge.

\section{Statement of Problem}

The study was conducted to determine the factors that influence financial literacy among the salaried in Bangalore. Despite basic education, the salaried class lack knowledge on managing money. There are various factors which can assist in inculcating the knowledge. The factors that were prominent from the literature were demographic factors, behavioural factors, financial attitude, and influential factors. The study aims to find whether financial literacy is associated with any of the above factors.

\subsection{Objectives}

1. To determine the various factors determining financial literacy

2. To find out the relationship between the factors visà-vis financial literacy

3. To identify prominent factor's for facilitating financial literacy

4. To provide insights of factors facilitating financial literacy to enable efficient inclusion.

\subsection{Research Hypothesis}

$\mathbf{H}_{\mathbf{0 1}}$ : Behavioural factors do not influence financial literacy

$\mathbf{H}_{\mathbf{0} 2}$ : No relationship exists between financial knowledge and financial literacy

$\mathbf{H}_{\mathbf{0 3}}$ : No relationship exists between financial attitude and financial literacy

$\mathbf{H}_{\mathbf{0 4}}$ : No relationship exists between Influential factors and financial literacy

\subsection{Methodology}

The study was focused to the salaried class working in Bangalore, to find insights of their influencing factors. The primary research by means of questionnaire was used to obtain the responses through google forms. The research was descriptive and the responses majorly used Likert scales for obtaining their responses. The sample size of the study was 70 . The sample was selected, such that it suffices the adequacy of scale validity and reliability. The tools used for analysis were Confirmatory factor analysis using Structural equation modelling. SPSS Amos Version 22 \& SPSS Version 20 were used for the analysis.

\subsubsection{Factors determining Financial Literacy}

The various determinants were observed from the review of previous studies and are capitulated as the factors that influence the financial literacy of an individual. 


\subsubsection{Demographic Factors}

Demographic factors included were age, gender, education, experience, income, profession, nature of employment, etc. Such characteristics contribute to be the demographic profile of the respondents that affect financial literacy. For example, if gender is one factor in the analysis, it is found that male respondents tend be more financially literate than the female respondents Annamaria Lusardi et. al, 2009.

\subsubsection{Socioeconomic Factors}

Socioeconomic factors include occupation, personal income, status and type, other wealth factors, etc. The questionnaire was structured to facilitate socioeconomic factors as a latent variable predicting financial literacy among the salaried individuals.

\subsubsection{Background Factors}

Background factors include upbringing of the family, experiences in childhood, employment security, relationships, location, life changing events, health, and access to credit, etc. Depending upon an individual's upbringing and family, the individual is said to be financially literate, i.e., if the parents are financially literate, they tend to teach the importance of finance management to their children, thus affecting financial literacy.

\subsubsection{Behavioral Factors}

Behavioral factors include self-confidence, esteem, future change, future prosperity, etc. These factors also contribute to influencing financial literacy among the individuals.

\subsubsection{Financial Attitude}

Financial attitude is one factor which includes topics relating to whether an individual can manage his own finances, or whether they are interested to develop the skills of thinking or increase thinking ability to increase knowledge on topics they are interested in.

\subsubsection{Financial Influences}

Financial influences refer to influences of family, friends, peers, etc. on an individual, whether to manage money or take appropriate decisions. Influences could be from formal tools which is financial experts or from informal tools which is family and peers. Influences could also be from a mentor.

\subsubsection{Other Factors}

Other factors which could help determine an individual's financial literacy is hopelessness, religiosity, and financial satisfaction. Hopelessness refers to the negative effect on components of financial behavior and well-being. In other words, over indebted individuals often tend to take rash decisions. Religiosity refers to the degree to which a person adheres to his/her religious beliefs, values, etc. financial satisfaction refers to the amount of wealth earned and owned by an individual to meet his/her living obligations.

Therefore, these are the factors that help determine factors predicting an individual's financial literacy. These were identified from the review of literature; certain factors might not be able to help determine financial literacy but such factors might influence other factors to determine the financial literacy of an individual.

\section{Data Analysis and Interpretation}

The questionnaire was drafted using Google forms \& convenient sampling technique was used to obtain responses. The design for the questionnaire was based on factors determining financial literacy namely, Financial attitude, behavioural, influence and financial knowledge.

The responses were coded in excel followed by adequacy test using SPSS version 20. The Kaiser Meyer Olkin test and Bartlett's test were used to check sampling adequacy.

\section{Table 1. KMO and Bartlett's Test}

\begin{tabular}{|l|l|l|}
\hline Kaiser-Meyer-Olkin Measure of Sampling Adequacy. & .491 \\
\hline \multirow{3}{*}{$\begin{array}{l}\text { Bartlett's Test of } \\
\text { Sphericity }\end{array}$} & Approx. Chi-Square & 741.805 \\
\cline { 2 - 3 } & $\mathrm{df}$ & 435 \\
\cline { 2 - 3 } & Sig. & .000 \\
\hline
\end{tabular}

The responses were obtained from 70 respondents, the sampling adequacy is satisfied in case of P-value using Bartlett's test, but the KMO test requires a value above 
0.60. (the observed value was 0.491 ) The factors were individually checked for loadings and a significantly larger value was considered appropriate to measure the latent variable. SPSS Amos version 22 was used for the further analysis.

Factor 1. Financial Attitude

\begin{tabular}{|l|l|l|}
\hline \multicolumn{3}{|c|}{ KMO and Bartlett's Test } \\
\hline Kaiser-Meyer-Olkin Measure of Sampling Adequacy. & .694 \\
\hline Bartlett's Test of Sphericity & Approx. Chi-Square & 92.271 \\
\cline { 2 - 3 } & df & 15 \\
\cline { 2 - 3 } & Sig. & .000 \\
\hline
\end{tabular}

The sample was found adequate for the factor Financial attitude, it can be observed from KMO value of 0.694 and from Bartlett's test p-value of 0.000 .

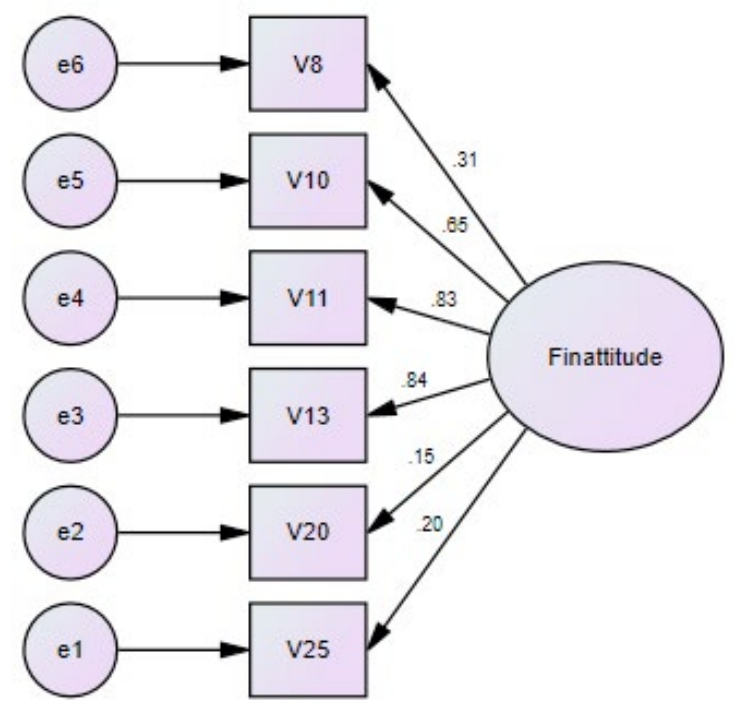

Model Fit estimates for financial attitude are as given below;

Table 1.1. Financial Attitude

\begin{tabular}{|l|l|l|l|l|l|}
\hline Model & NPAR & CMIN & DF & P & CMIN/DF \\
\hline Default model & 12 & 9.401 & 9 & .401 & 1.045 \\
\hline Saturated model & 21 & .000 & 0 & & \\
\hline Independence model & 6 & 96.163 & 15 & .000 & 6.411 \\
\hline
\end{tabular}

The P-value of the factor loadings is 0.401 which is greater than $5 \%$, hence we conclude that the model is adequate. The CMIN/DF value is also well below 3 (Hair et. al, 2010), which aids in concluding the same.
Table 1.2. Financial Attitude

\begin{tabular}{|l|l|l|l|l|}
\hline Model & RMR & GFI & AGFI & PGFI \\
\hline Default model & .075 & .957 & .900 & .410 \\
\hline Saturated model & .000 & 1.000 & & \\
\hline Independence model & .251 & .673 & .542 & .481 \\
\hline
\end{tabular}

The goodness of fit indices observed using GFI \& AGFI is adequate for justifying the factor loadings. The same can be observed by a RMR value of 0.075 (less than 0.1 ). The value of GFI, AGFI, CFI, and NFI should range from 0.80 to 0.89 to render the model as absolutely acceptable and if the value exceeds 0.90 , the model shall be considered as very good fit Hair et. al, (2010)

Table 1.3. Financial Attitude

\begin{tabular}{|l|c|c|c|c|}
\hline Model & RMSEA & L0 90 & HI 90 & PCLOSE \\
\hline Default model & .025 & .000 & .138 & .536 \\
\hline Independence model & .278 & .226 & .332 & .000 \\
\hline
\end{tabular}

The Root mean square error is 0.025 , a value below 0.05 is recommended for an appropriate loading of a factor. The value of RMSEA should not exceed 0.08 Hair et. al, (2010).

Factor 2: Behavioural factors

\begin{tabular}{|ll|l|}
\hline \multicolumn{2}{|c|}{ KMO and Bartlett's Test } \\
\hline Kaiser-Meyer-Olkin Measure of Sampling Adequacy. & .612 \\
Bartlett's Test of Sphericity $\quad$ Approx. Chi-Square & 61.203 \\
& df & 10 \\
& Sig. & .000 \\
\hline
\end{tabular}

The sample was found adequate for the behavioural factor, it can be observed from KMO value of 0.694 and from Bartlett's test p-value of 0.000 .

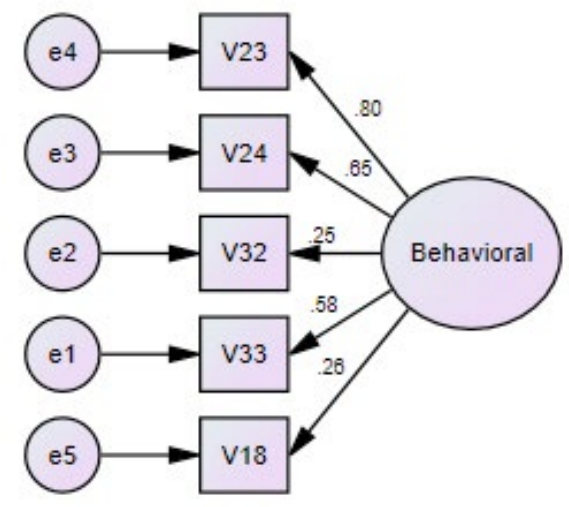


Model Fit estimates for behaviour are as given below;

Table 2.1. Behaviour

\begin{tabular}{|l|c|c|c|c|c|}
\hline Model & NPAR & \multicolumn{1}{c|}{ CMIN } & DF & P & CMIN/DF \\
\hline Default model & 10 & 15.551 & 5 & .008 & 3.110 \\
\hline Saturated model & 15 & .000 & 0 & & \\
\hline Independence model & 5 & 63.470 & 10 & .000 & 6.347 \\
\hline
\end{tabular}

The $\mathrm{P}$-value of the factor loadings is 0.008 which is less than $5 \%$, hence we conclude that the model must be modified/corrected. The CMIN/DF value is observed below 3 (Hair et. al, 2010), which is a moderately adequate sigh to use the factor.

Table 2.2. Behaviour

\begin{tabular}{|l|c|c|c|c|}
\hline Model & RMR & GFI & AGFI & PGFI \\
\hline Default model & .296 & .919 & .758 & .306 \\
\hline Saturated model & .000 & 1.000 & & \\
\hline Independence model & .813 & .725 & .587 & .483 \\
\hline
\end{tabular}

The goodness of fit indices observed using GFI is adequate, but the AGFI is slightly lesser than 0.90 for justifying the factor loadings. The RMR value of 0.025 (less than 0.1 ) as well suggest a moderate loading. The value of GFI, AGFI, CFI, and NFI should range from 0.80 to 0.89 to render the model as absolutely acceptable and if the value exceeds 0.90 , the model shall be considered as very good fit Hair et. al, (2010).

Table 2.3. Behaviour

\begin{tabular}{|l|c|c|c|c|}
\hline Model & RMSEA & L0 90 & HI 90 & PCLOSE \\
\hline Default model & .174 & .080 & .275 & .020 \\
\hline Independence model & .276 & .214 & .343 & .000 \\
\hline
\end{tabular}

The Root mean square error is 0.174 , a value above 0.05 suggests a correction for appropriate loading of a factor. The value of RMSEA should not exceed 0.08 (Hair et. al, 2010). Variable $32 \&$ variable 18 were found with regression weights of $0.25 \& 0.26$ respectively and were removed as the minimum criteria for proper loading is 0.50 . The factor is reiterated with the other 3 variables.

Factor 3: Influential factors

\begin{tabular}{|ll|l|}
\hline \multicolumn{2}{|c|}{ KMO and Bartlett's Test } \\
\hline Kaiser-Meyer-Olkin Measure of Sampling Adequacy. & .652 \\
Bartlett's Test of Sphericity & Approx. Chi-Square & 43.059 \\
& df & 15 \\
& Sig. & .000 \\
\hline
\end{tabular}

The sample was found adequate for the Influential factor, it can be observed from KMO value of 0.652 and from Bartlett's test p-value of 0.000 .

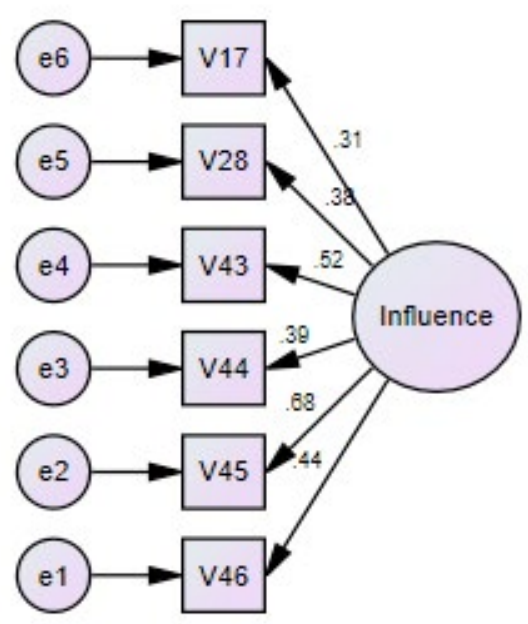

Model Fit estimates for Influential factors;

Table 3.1. Influential factors

\begin{tabular}{|l|r|r|c|c|c|}
\hline Model & NPAR & CMIN & DF & P & CMIN/DF \\
\hline Default model & 12 & 9.583 & 9 & .385 & 1.065 \\
\hline Saturated model & 21 & .000 & 0 & & \\
\hline Independence model & 6 & 44.875 & 15 & .000 & 2.992 \\
\hline
\end{tabular}

The P-value of the Default Model is 0.385 which is more than $5 \%$, hence we conclude that the model is adequate. The CMIN/DF value is also observed below 3 Hair et. al, (2010), which substantiates the model fit.

Table 3.2. Influential factors

\begin{tabular}{|l|l|l|l|l|}
\hline Model & RMR & GFI & AGFI & PGFI \\
\hline Default model & .114 & .959 & .905 & .411 \\
\hline Saturated model & .000 & 1.000 & & \\
\hline Independence model & .351 & .795 & .712 & .568 \\
\hline
\end{tabular}

The goodness of fit indices observed using GFI \& AGFI is adequate for justifying the factor loadings. The RMR value is 0.114 (slightly higher than 0.1 ), suggesting a modification. The value of GFI, AGFI, CFI, and NFI should range from 0.80 to 0.89 to render the model as absolutely acceptable and if the value exceeds 0.90 , the model shall be considered as very good fit Hair et. al, (2010). 
Table 3.3. Influential factors

\begin{tabular}{|l|l|l|l|l|}
\hline Model & RMSEA & L0 90 & HI 90 & PCLOSE \\
\hline Default model & .030 & .000 & .140 & .521 \\
\hline Independence model & .169 & .113 & .227 & .001 \\
\hline
\end{tabular}

The Root mean square error is 0.030 , a value below 0.05 is recommended for an appropriate loading of a factor. 3 variables were found cross loaded with the factor financial literacy and were removed to justify proper loading.

Factor 4: Financial knowledge

\begin{tabular}{|ll|l|}
\hline \multicolumn{2}{|c|}{ KMO and Bartlett's Test } \\
\hline Kaiser-Meyer-Olkin Measure of Sampling Adequacy. & .615 \\
Bartlett's Test of Sphericity & Approx. Chi-Square & 41.019 \\
& df & 6 \\
& Sig. & .000 \\
\hline
\end{tabular}

The sample was found adequate for the Influential factor, it can be observed from KMO value of 0.615 and from Bartlett's test p-value of 0.000 .

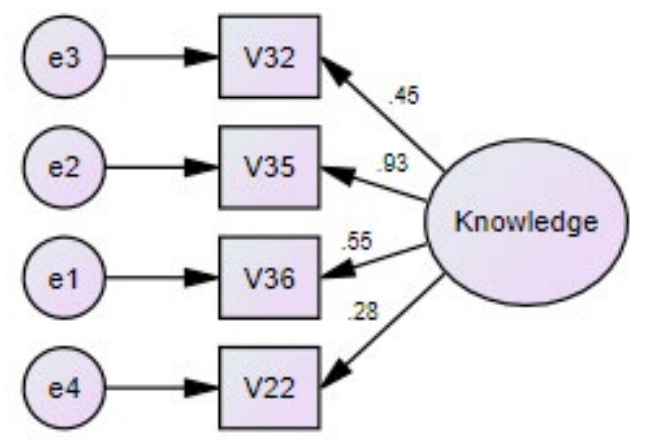

Model Fit estimates for Financial Knowledge;

Table 4.1. Financial knowledge

\begin{tabular}{|l|l|l|l|l|l|}
\hline Model & NPAR & CMIN & DF & P & CMIN/DF \\
\hline Default model & 8 & 1.721 & 2 & .423 & .861 \\
\hline Saturated model & 10 & .000 & 0 & & \\
\hline Independence model & 4 & 42.329 & 6 & .000 & 7.055 \\
\hline
\end{tabular}

The P-value of the Default Model is 0.423 which is more than 5\%, hence we conclude that the model is fit. The CMIN/DF value is also observed below 5, which substantiates the model fit.
Table 4.2. Financial knowledge

\begin{tabular}{|l|c|c|c|c|}
\hline Model & RMR & GFI & AGFI & PGFI \\
\hline Default model & .089 & .988 & .938 & .198 \\
\hline Saturated model & .000 & 1.000 & & \\
\hline Independence model & .509 & .760 & .600 & .456 \\
\hline
\end{tabular}

The goodness of fit indices observed using GFI \& AGFI are greater than 0.90 , adequately justifying the factor loadings. The RMR value is 0.089 (less than 0.1 ), suggesting a good model fit.

Table 4.3. Financial knowledge

\begin{tabular}{|l|c|c|c|c|}
\hline Model & RMSEA & L0 90 & HI 90 & PCLOSE \\
\hline Default model & .000 & .000 & .226 & .484 \\
\hline Independence model & .294 & .214 & .381 & .000 \\
\hline
\end{tabular}

The Root mean square error is 0.000 , a value below 0.05 is recommended for an appropriate loading of a factor. The error is the least, signifying the best fit.

Factor 5: Financial literacy

\begin{tabular}{|ll|l|}
\hline \multicolumn{2}{|c|}{ KMO and Bartlett's Test } \\
\hline Kaiser-Meyer-Olkin Measure of Sampling Adequacy. & .641 \\
Bartlett's Test of Sphericity & Approx. Chi-Square & 25.267 \\
& df & 6 \\
& Sig. & .000 \\
\hline
\end{tabular}

The sample was found adequate for the Financial Literacy, it can be observed from KMO value of 0.641 and from Bartlett's test p-value of 0.000 .

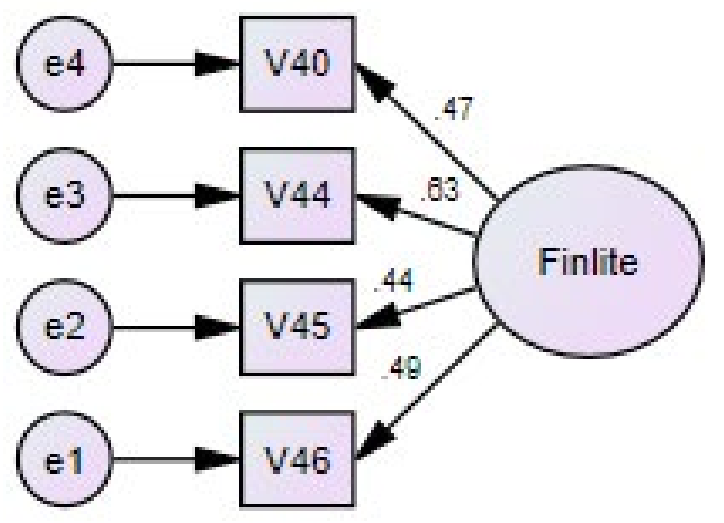

Model Fit estimates for Financial literacy 
Table 5.1. Financial literacy

\begin{tabular}{|l|l|l|l|l|l|}
\hline Model & NPAR & CMIN & DF & P & CMIN/DF \\
\hline Default model & 8 & 2.881 & 2 & .237 & 1.440 \\
\hline Saturated model & 10 & .000 & 0 & & \\
\hline Independence model & 4 & 26.074 & 6 & .000 & 4.346 \\
\hline
\end{tabular}

The P-value of the Default Model is 0.237 which is more than $5 \%$, hence we conclude that the model is fit. The CMIN/DF value is also observed below 3 (Hair et. al, 2010), which substantiates the model fit.

Table 5.2. Financial literacy

\begin{tabular}{|l|c|c|c|c|}
\hline Model & RMR & GFI & AGFI & PGFI \\
\hline Default model & .094 & .979 & .895 & .196 \\
\hline Saturated model & .000 & 1.000 & & \\
\hline Independence model & .378 & .823 & .706 & .494 \\
\hline
\end{tabular}

The goodness of fit indices observed using GFI \& AGFI. GFI is greater than 0.90 , and AGFI 0.895 justifying adequate factor loadings. The RMR value is 0.094 (less than 0.1 ), suggesting a good model fit.

Table 5.3. Financial literacy

\begin{tabular}{|l|l|l|l|l|}
\hline Model & RMSEA & L0 90 & HI 90 & PCLOSE \\
\hline Default model & .079 & .000 & .264 & .295 \\
\hline Independence model & .219 & .137 & .308 & .001 \\
\hline
\end{tabular}

The Root mean square error is 0.079 , a value below 0.05 is recommended for an appropriate loading of a factor. The error is signifying the best fit.

\section{Model Building: Model 1: Behaviour influences Financial Literacy:}

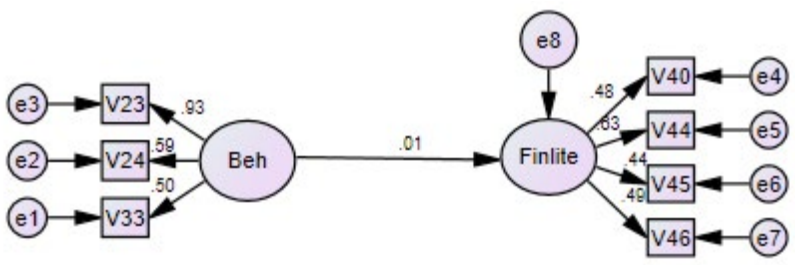

Behaviour influences Financial literacy and the coefficient of influence is 0.01 , Financial literacy is the dependent variable predicted by the dependent factor behaviour. The error term is added to the Financial literacy.

\section{Model 2: Financial attitude influences Financial Literacy:}

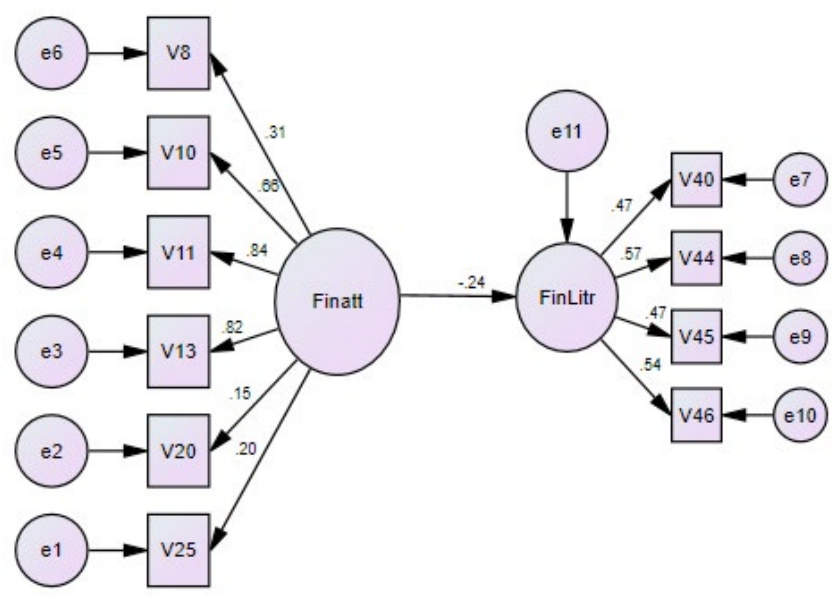

Financial attitude influences Financial literacy and the co-efficient of influence is -0.24 , Financial literacy is the dependent variable predicted by the dependent factor financial attitude.

\section{Model 3: Financial Knowledge Influences Financial Literacy:}

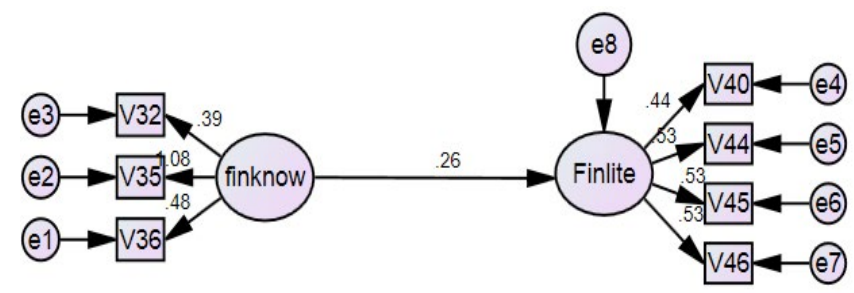

\begin{tabular}{|l|l|l|l|l|l|}
\hline Model & NPAR & CMIN & DF & P & CMIN/DF \\
\hline Default model & 15 & 15.610 & 13 & .271 & 1.201 \\
\hline Saturated model & 28 & .000 & 0 & & \\
\hline Independence model & 7 & 77.453 & 21 & .000 & 3.688 \\
\hline
\end{tabular}

\begin{tabular}{|l|l|l|l|l|}
\hline Model & RMR & GFI & AGFI & PGFI \\
\hline Default model & .135 & .942 & .874 & .437 \\
\hline Saturated model & .000 & 1.000 & & \\
\hline Independence model & .388 & .757 & .676 & .568 \\
\hline
\end{tabular}

\begin{tabular}{|l|l|l|l|l|}
\hline Model & RMSEA & L0 90 & HI 90 & PCLOSE \\
\hline Default model & .054 & .000 & .136 & .427 \\
\hline Independence model & .196 & .150 & .244 & .000 \\
\hline
\end{tabular}


Regression Weights: (Group number 1 - Default model)

\begin{tabular}{|l|l|l|c|c|c|c|c|}
\hline & & & Estimate & S.E. & C.R. & $P$ & Label \\
\hline Finlite & $<---$ & finknow & .193 & .129 & 1.498 & .134 & \\
\hline V36 & $<---$ & finknow & 1.000 & & & & \\
\hline V35 & $<---$ & finknow & 1.887 & .893 & 2.114 & .035 & \\
\hline V32 & $<---$ & finknow & .955 & .313 & 3.047 & .002 & \\
\hline V40 & $<---$ & Finlite & 1.000 & & & & \\
\hline V44 & $<---$ & Finlite & 1.310 & .592 & 2.215 & .027 & \\
\hline V45 & $<---$ & Finlite & 1.433 & .647 & 2.215 & .027 & \\
\hline V46 & $<---$ & Finlite & 1.422 & .643 & 2.212 & .027 & \\
\hline
\end{tabular}

The financial knowledge aids in predicting $26 \%$ of the variation in Financial literacy. The model is adequate as observed by CMIN/DF, P-value of 0.271 , GFI, AGFI \& RMSEA. The p-value of regression weight of Financial knowledge to Financial literacy is 0.134 and a P-value of 0.05 would be said to be a significant model.

Model 4: Influence predicting Financial Literacy:

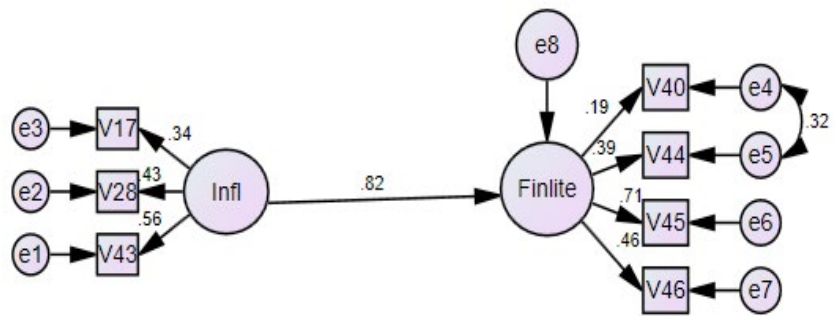

\begin{tabular}{|l|l|l|l|l|l|}
\hline Model & NPAR & CMIN & DF & P & CMIN/DF \\
\hline Default model & 16 & 11.987 & 12 & .447 & .999 \\
\hline Saturated model & 28 & .000 & 0 & & \\
\hline Independence model & 7 & 57.698 & 21 & .000 & 2.748 \\
\hline
\end{tabular}

\begin{tabular}{|l|l|l|l|l|}
\hline Model & RMR & GFI & AGFI & PGFI \\
\hline Default model & .107 & .956 & .897 & .410 \\
\hline Saturated model & .000 & 1.000 & & \\
\hline Independence model & .333 & .783 & .711 & .587 \\
\hline
\end{tabular}

\begin{tabular}{|l|l|l|l|l|}
\hline Model & RMSEA & L0 90 & HI 90 & PCLOSE \\
\hline Default model & .000 & .000 & .122 & .601 \\
\hline Independence model & .158 & .110 & .207 & .000 \\
\hline
\end{tabular}

Regression Weights: (Group number 1 - Default model)

\begin{tabular}{|l|l|l|r|r|c|c|c|}
\hline & & & Estimate & S.E. & C.R. & P & Label \\
\hline Finlite & $<---$ & Infl & .308 & .278 & 1.106 & .269 & \\
\hline V43 & $<---$ & Infl & 1.000 & & & & \\
\hline V28 & $<---$ & Infl & 1.094 & .500 & 2.187 & .029 & \\
\hline V17 & $<---$ & Infl & .717 & .380 & 1.885 & .059 & \\
\hline V40 & $<---$ & Finlite & 1.000 & & & & \\
\hline V44 & $<---$ & Finlite & 2.261 & 1.689 & 1.338 & .181 & \\
\hline V45 & $<---$ & Finlite & 4.522 & 3.732 & 1.212 & .226 & \\
\hline V46 & $<---$ & Finlite & 2.917 & 2.446 & 1.192 & .233 & \\
\hline
\end{tabular}

Influence predicts $82 \%$ of the variation in Financial literacy. The model is adequate as observed by CMIN/ DF, P-value of 0.447, GFI, AGFI \& RMSEA. The p-value of regression weight of Influence to Financial literacy is 0.269 and a P-value of 0.05 would be said to be a significant model.

\section{Model 5: Influence and Financial knowledge predicting Financial Literacy}

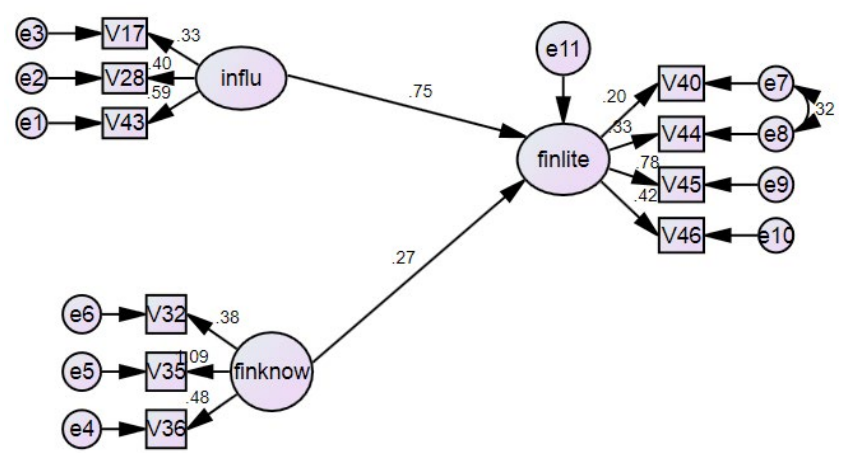

\section{Model Fit Summary:}

\begin{tabular}{|l|l|l|l|l|l|}
\hline Model & NPAR & CMIN & DF & P & CMIN/DF \\
\hline Default model & 23 & 40.768 & 32 & .138 & 1.274 \\
\hline Saturated model & 55 & .000 & 0 & & \\
\hline Independence model & 10 & 126.937 & 45 & .000 & 2.821 \\
\hline
\end{tabular}

\begin{tabular}{|l|l|l|l|l|}
\hline Model & RMR & GFI & AGFI & PGFI \\
\hline Default model & .170 & .901 & .831 & .524 \\
\hline Saturated model & .000 & 1.000 & & \\
\hline Independence model & .351 & .728 & .668 & .596 \\
\hline
\end{tabular}

\begin{tabular}{|l|l|l|l|l|}
\hline Model & RMSEA & L0 90 & HI 90 & PCLOSE \\
\hline Default model & .063 & .000 & .114 & .340 \\
\hline
\end{tabular}




\begin{tabular}{|l|l|l|l|l|}
\hline Model & RMSEA & L0 90 & HI 90 & PCLOSE \\
\hline Independence model & .161 & .129 & .195 & .000 \\
\hline
\end{tabular}

The Model fit is observed from a CMIN/DF value of 1.274 along with the P-value of 0.138 (more than 0.05). The model has a goodness of fit index of 0.9 and a moderately higher AGFI. The RMSEA was 0.063, significantly lower than $10 \%$ level.

\section{Findings and Implications}

The research paper proves that among the four factors considered, financial knowledge and influence determined financial literacy. Financial knowledge had a predictable coefficient of 0.27 and influence a coefficient of 0.75 . These insights from the paper can be considered to increase the financial literacy level among the employed. A higher financial literacy can be achieved if the factors are determined. Increase of financial knowledge can be monitored through initiatives like financial literacy programs, role plays, case studies from practical investments which can develop skills on better financial planning. The paper emphasizes on the need to create awareness about effective financial planning by using the significant factors. Policy makers can concentrate to develop training programs to influence the decision maker.

\section{Conclusion}

The research demonstrates the key factors that influenced financial literacy. Among the factors a positive relationship was observed between behavioural factors, financial knowledge, and influence. It was observed that the behavioural factor though positive only had a $1 \%$ influence on financial literacy, which is in-line with prior studies on behavioural factors. In case of financial attitude, the effect was negative on financial literacy. Financial knowledge and influence was found majorly predicting financial literacy. The factors were observed in prior studies on financial decision making. The core of an effective financial inclusion is the degree of financial literates among the salaried. An efficient financial planning could be facilitated if the financial literacy levels are high. In order to achieve it, we can use the knowledge factors and the influence factors.

\section{Limitations and Scope for Further Research}

The data collected was limited to 70 respondents due to the availability of time. Primary data was collected from respondents and the response can differ if we consider large samples. The factors were limited to four as they were found prominent in the literature. Influence as a factor can be categorised to observe which among them could better facilitate the process. The success of training programs on increasing knowledge can be studied for cost effective way of imparting financial literacy.

\section{Bibliography}

Aren, S. (2014). A literature review on financial literacy, 33-50. Available from crossref

Barbara, M. B. (2010). Structural equation modelling with AMOS. Routledge, 53-127

Bhushan, P., \& Medury, Y. (2013). Financial literacy and its determinants. International Journal of Engineering, Business, and Enterprise Applications, 4(2), 155-60.

Das, S. (2016). Financial literacy: measurement and determinants, 88-93. Avaliable from crossref

Fatemeh, K. \& Stanley Y. (2017). Level of financial literacy in Malaysia. International Journal of Research. Availabel from: crossref

Hair, J. F. et al. (2010). Multivariate data analysis, Pearson education, 627-87.

Islamoglu, M. et al. (2015). Determination of Factors Affecting Individual Investor Behaviours: A Study on Bankers, 5(2), 531-43. Available from: crossref > Home > Vol 5, No 2 (2015) > İslamoğlu

Kharchenko, O. (2011). Financial literacy in Ukraine: Determinants and implications for saving behavior. (Doctoral dissertation, Kyiv School of Economics). Avbailable from: crossref

Lusardi, A., Mitchell, O. S., \& Curto, V. (2009). Financial literacy among the young: Evidence and implications for consumer policy. (No. w15352). National Bureau of Economic Research. Available from crossref crossref crossref 
Mbarire, T. T., \& Ali, A. I. (2014). Determinants of financial literacy levels among employees of Kenya Ports Authority in Kenya. Research Journal of Finance and Accounting, 5(16), 44-52.

OECD, International Network on Financial Education. (2011). crossref

OECD, The Importance of Financial education. (2006). Available from crossref

Rasoaisi, L., \& Kalebe, K.M. (2015). Determinants of Financial Literacy among the National University of Lesotho Students. Asian Economic and Financial Review, 5(9), 1050-60. crossref
Sabri, M. F et. al. (2010). Childhood consumer experience and thefinancialliteracy of collegestudentsin Malaysia.Family and Consumer Sciences Research Journal, 38(4), 455-67 crossref

Sucuahi, W. T. (2013). Determinants of financial literacy of micro entrepreneurs in Davao City. International Journal of Accounting Research, 1(1), 44-51. crossref

Vyvyan, V., Blue, L., \& Brimble, M. (2014). Factors that Influence Financial Capability and Effectiveness: Expl -oring FinancialCounsellors'Perspectives.Australasian Accounting Business \& Finance Journal, 8(4), 3. crossref 